\title{
Experimental Investigation on Corrosion Effect on Mechanical Properties of Buried Metal Pipes
}

\author{
Yingbo Hou, ${ }^{1}$ Deqing Lei, ${ }^{1}$ Shujin Li, ${ }^{1}$ Wei Yang, ${ }^{1}$ and Chun-Qing $\mathrm{Li}^{2}$ \\ ${ }^{1}$ School of Civil Engineering and Architecture, Wuhan University of Technology, Wuhan 430070, China \\ ${ }^{2}$ School of Engineering, RMIT University, Melbourne, VIC 3001, Australia \\ Correspondence should be addressed to Chun-Qing Li; chunqing.li@rmit.edu.au
}

Received 20 June 2016; Revised 5 August 2016; Accepted 8 August 2016

Academic Editor: Flavio Deflorian

Copyright (c) 2016 Yingbo Hou et al. This is an open access article distributed under the Creative Commons Attribution License, which permits unrestricted use, distribution, and reproduction in any medium, provided the original work is properly cited.

\begin{abstract}
Corrosion has been found to be the most predominant cause for failures of buried metal pipes. A review of published literature on pipe corrosion reveals that little research has been undertaken on the effect of corrosion on mechanical properties of pipe materials and almost no research has been conducted on corrosion effect on fracture toughness. The intention of this paper is to present a comprehensive test program designed to investigate the effect of corrosion on mechanical properties of metals in soil. Two types of metals, namely, cast iron and steel, are tested under corrosion in three different environments. A relationship between corrosion and deterioration of mechanical property of metals is developed. It is found in the paper that the more acidic the environment is, the more corrosion the metal undergoes and that the corrosion reduces both the tensile strength and fracture toughness of the metal. The results presented in the paper can contribute to the body of knowledge of corrosion behavior and its effect on mechanical properties of metals in soil environment, which in turn enable more accurate prediction of failures of buried metal pipes.
\end{abstract}

\section{Introduction}

Pipelines are essential infrastructure that play a significant role in a nation's economy, social well-being, and quality of life. Most of pipes are made of metals, for example, cast iron and steel, and located underground in soil. It is estimated that about $85 \%$ of water distribution pipes are cast iron and steel [1]. Due to their long-term service and exposure to aggressive environment in soil, aging and deterioration of metal pipes have resulted in an unexpected high rate of failures. For example, the failure rate of cast iron pipes can be as high as 39 bursts per $100 \mathrm{~km}$ per year in Canada [2] whilst the failure rate of water mains in Australia is 20 breaks per $100 \mathrm{~km}$ per year on average [3]. As is well appreciated, the consequence of pipe failures can be socially, economically, and environmentally catastrophic, resulting in massive disruption of daily life, considerable economic loss, widespread flooding, and subsequent environmental pollution and even casualties and so forth. Therefore, there is a well-justified need to thoroughly investigate the causes of pipe failures.

Experience and investigation of pipe failures suggest that corrosion of metals, both cast iron and steel, is the most predominant cause of pipe failures $[4,5]$. Since corrosion is linked to almost all pipe failures, it has become a global problem for all stakeholders, in particular engineers and asset managers of buried metal pipes [6, 7]. As such, considerable research has been undertaken in the past few decades on corrosion of metal pipes, more perhaps for cast iron pipes, as represented notably by Doleac et al. [8], Dean Jr. and Grab [9], O'Day et al. [10], Randall-Smith et al. [11], Kirmeyer et al. [12], Camarinopoulos et al. [13], Sadiq et al. [14], Panossian et al. [15], and so on. Due to different environments, the mechanisms of corrosions are different for internal and external surfaces of the pipe. For internal corrosion, depending on the substance to be conveyed in the pipe, various factors, including microbial effects, can cause corrosion [16], whereas external corrosion is mainly due to corrosive chemicals in soil [17]. Pipe corrosion in soil is an interaction between the pipe materials and the soil environment [18]. There are several stimulating factors that lead to the pipe external corrosion in soil environment $[5,19]$. Moisture, temperature, $\mathrm{pH}$ values, mineral salt content, sulfides, organics, precipitates, and so on are major factors that contribute to external corrosion of 
pipes in soil [20]. Metal corrosion in soils is determined primarily by a combined effect of these factors. It also depends on the physical and chemical characteristics of the soils.

A review of published literature on pipe corrosion, as cited above (and also see references), reveals that most of the current research focuses on corrosion mechanisms, corrosion progress, and corrosion rate from material perspective. Little research has been undertaken on the effect of corrosion on mechanical property change of pipe materials, and almost no research has been conducted on corrosion effect on fracture toughness of pipe materials. As is well known, it is the mechanical properties of the pipe materials that govern the behavior and eventual failure of the pipes. It is therefore imperative to thoroughly examine the effect of metal corrosion on its mechanical properties. The understanding and knowledge of corrosion induced deterioration of mechanical properties of metals can prevent future failures of metal pipes.

There are two main modes of pipe failure: by rupture due to the reduction of wall thickness of the pipes and by fracture due to the stress concentration at the tips of cracks, for example, corrosion pits or, in general, defects in the pipes [21]. The mechanical properties corresponding to these two failure modes are tensile strength and fracture toughness of the metal. A detailed examination of most published research in this area (see references) suggests that current research on corrosion induced pipe failures focuses more on loss of strength than toughness. An inspection of failures of trunk mains in service reveals that most cast iron water main failures are of fracture type; that is, the failure is caused by the growth of a crack and subsequent collapse of the pipe [22]. It is therefore essential to study the deterioration of both tensile strength and fracture toughness of the metals to enable more accurate prediction of pipe failures.

The intention of this paper is to experimentally investigate the effect of corrosion on mechanical properties of metals used as pipe material. A comprehensive test program is designed to observe, monitor, and evaluate corrosion behavior of metals and its effect on their mechanical properties in different environments. Two types of metals, namely, cast iron and steel, are tested under corrosion in three environments as represented by $\mathrm{pH}$ values. From the analysis of test results, a relationship between corrosion and deterioration of mechanical property of metals is developed. It is believed that tests on the effect of corrosion on mechanical properties of metals are one of few of the kind. The results produced from the tests can contribute to the body of knowledge of corrosion behavior and its effect on mechanical properties of metal in soil environment, which can equip engineers and asset managers in mitigating the risk of failures of metal pipes.

\section{Design of Test Specimens}

2.1. Specimen Materials. Cast iron and steel have been the most predominant pipeline material before the 1980s [21]. Among various types of cast irons and steel, grey cast iron and carbon steel are perhaps the most widely used pipe materials $[12,23]$. Because of this, it is reasonable to select these two types of materials for corrosion investigation due to their wide use and also long service. Cast iron and steel have quite
TABLE 1: Chemical composition of test materials (wt.\%).

\begin{tabular}{lccccc}
\hline Material & $\mathrm{C}$ & $\mathrm{S}$ & $\mathrm{P}$ & $\mathrm{Mn}$ & $\mathrm{Si}$ \\
\hline Q235 steel & 0.176 & 0.023 & 0.019 & 0.465 & 0.233 \\
HT200 cast iron & 3.2 & 0.12 & 0.015 & 0.9 & 1.6 \\
\hline
\end{tabular}

different mechanical properties although they have been used for the same purpose of pipes. Cast iron is brittle material whilst steel is ductile. Cast iron has been widely used in pipeline industry due to its comparatively low cost but it has been replaced by steel in pipeline industry for its greater strength and ductility.

As is well known, the mechanical properties of metal are affected by its chemical composition, morphology, and microstructure which vary significantly. In this study, Q235 plain carbon steel and HT200 grey cast iron are selected as the testing materials due to their wide use in pipe industry in China and availability on market $[1,24]$. The chemical composition of Q235 steel and HT200 cast iron is shown in Table 1.

2.2. Specimens for Tensile Strength. Specimens for tensile strength test were made according to ASTM E8M13 Standard Test Methods for Tension Testing of Metallic Materials [25]. The testing specimens are recommended single-edge bend $[\mathrm{SE}(\mathrm{B})]$ in the standard, of which the dimensions should comply with the following requirement:

$$
L \geq 4 D \text {, }
$$

where $L$ is the gauge length and $D$ is the diameter of the middle part of the specimen within gauge length $L$. For the sake of comparison, the specimens of the two different materials for tensile strength test are intentionally made with the same dimensions. The specimen for tensile strength is shown in Figure 1(a).

2.3. Specimens for Fracture Toughness. Specimens for fracture toughness test were made according to ASTM E1820-13 Standard Test Method for Measurement of Fracture Toughness [26]. In this standard the key is to control the width of the specimen since it is the most important factor that affects the resulting fracture toughness. Depending on the width of the specimens, there can be two types of fractures: the plane stress fracture and plane strain fracture. For the plane stress fracture, the fracture toughness decreases with the increase of specimen width and stabilizes at a certain width for which plane strain fracture occurs. This width is determined according to ASTM E1820-13 as follows:

$$
B \geq 2.5\left(\frac{K_{\mathrm{IC}}}{\sigma_{y}}\right)^{2},
$$

where $B$ is the width of the specimen, $K_{\text {IC }}$ is the fracture toughness, and $\sigma_{y}$ is the yield strength of the material.

By (2), the width for selected cast iron specimen with the grade HT200 was calculated to be $B=20 \mathrm{~mm}$. However, for the selected Q235 steel, the calculated width for the 


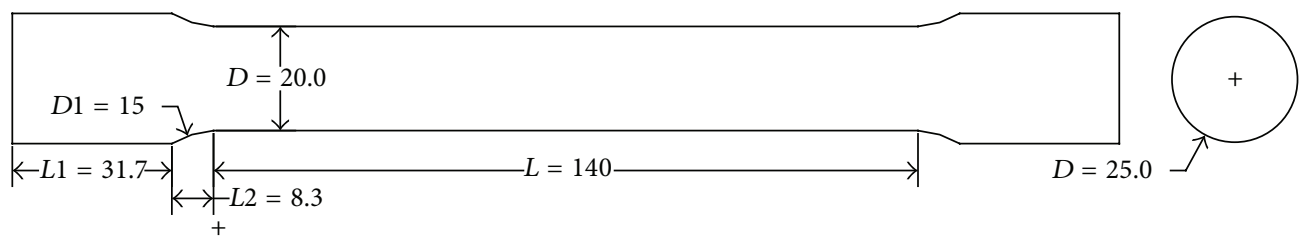

(a) For tensile strength
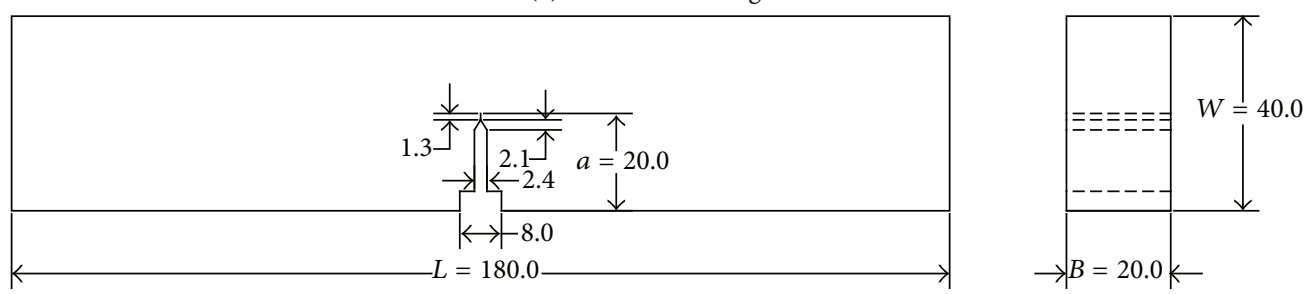

(b) For fracture toughness

FIGURE 1: Test specimen (unit: $\mathrm{mm}$ ).

test specimen is as large as $1700 \mathrm{~mm}$, which is too large to be practical for both corrosion and fracture tests. Since the primary purpose of this study is (1) to experimentally examine how corrosion affects the fracture toughness of the Q235 steel but not to determine its accurate value of fracture toughness and (2) to compare the corrosion effect on fracture toughness for different metals (i.e., steel and cast iron), it is justifiable to select a smaller but with same size as that for cast iron specimens for both corrosion and fracture toughness tests. This is because all test specimens should be under the same corrosion and fracture conditions and hence relative comparison of fracture toughness change over time and with each other is valid. Besides, the accurate value of fracture toughness of the Q235 steel has been determined with different methods as shown in, for example, Zhao et al. [27] and Dong et al. [28]. Small size specimens of steel for fracture toughness tests have also been used in other studies as shown in literature [29]. Therefore, the width of specimens for fracture toughness test for Q235 steel was selected the same as that for cast iron. The specimen for fracture toughness is shown in Figure 1(b).

2.4. Manufacture of Specimens. All test specimens were manufactured by specialist mechanical technicians. For tensile specimens the manufacture was straightforward. For fracture toughness, the specimens should theoretically be precracked by fatigue. Experience and literature survey have shown that it is impractical to obtain a reproducibly sharp, narrow machined notch that will simulate a natural crack well enough to provide a satisfactory fracture toughness test result [27]. The most effective alternative is to produce a precrack, a comparatively short fatigue crack, which is extended from a narrow notch. There are three forms of notches to start a fatigue crack (known as fatigue crack starter notch), which are straight through notch, chevron notch, and notch ending with drilled hole. Different forms of fatigue crack starter notches shall meet different dimension requirements. In this study, the straight through notch was employed as fatigue crack starter. For detailed specifications of specimen size, configuration, and preparation, refer to ASTM E1820 [26].
TABLE 2: Soluble chemical composition of soil sample (wt.\%).

\begin{tabular}{lcccc}
\hline Chemical & $\mathrm{CaO}$ & $\mathrm{MgO}$ & $\mathrm{K}_{2} \mathrm{O}$ & $\mathrm{Na}_{2} \mathrm{O}$ \\
\hline Content & 0.92 & 1.54 & 2.17 & 0.60 \\
\hline
\end{tabular}

TABLE 3: Chemical composition in simulated soil solutions (g/L).

\begin{tabular}{lcccc}
\hline Chemical & $\mathrm{CaCl}_{2} \cdot 2 \mathrm{H}_{2} \mathrm{O}$ & $\mathrm{MgSO}_{4} \cdot 7 \mathrm{H}_{2} \mathrm{O}$ & $\mathrm{KCl}$ & $\mathrm{NaHCO}_{3}$ \\
\hline Content & 0.036 & 0.190 & 0.069 & 0.540 \\
\hline
\end{tabular}

\section{Test Methodology}

3.1. Simulation of Corrosive Soil. Pipe corrosion is electrochemical reaction between the pipe material and the corrosive agents in the ambient soil. In order to represent this reaction in the laboratory, it is necessary to simulate the working environment of the pipes. There are two methods to simulate the working environment; one is to bury the pipe in a box of real soil and the other is to immerse the pipe in a solution that contains main chemical elements extracted from the real soil (known as soil solution). Literature reviews suggest that most of current research employs soil solutions for pipe corrosion test in soil [30, 31]. Therefore, this study also employed the soil solution for corrosion test. One advantage of using soil solution is the ease to control the testing variables and also monitoring of corrosion behavior.

For convenience, soil in local land with pipes underneath was selected. The chemical composition of the selected soil was analyzed and is shown in Table 2. This composition was used to make soil solution. The chemical analysis of the soil indicates that the $\mathrm{pH}$ of the soil is 8.0 . So the base solution used for corrosion test has $\mathrm{pH}$ of 8.0. The chemical composition of the soil solution used in the corrosion test is shown in Table 3 which was made based on the principle that the key chemical elements of soil sample and soil solution are the same [30, 31].

Since metal corrosion under natural soil conditions will take a long time to have any significant effect on its material properties and to achieve the research objective within the 
time period of the project, acceleration of corrosion appears to be necessary for almost all corrosion tests (e.g., $[5,32])$. Thus, acceleration of corrosion was adopted in this test. A literature review suggests that $\mathrm{pH}$ value will accelerate the corrosion of metal exponentially [33]. For this reason, three values of $\mathrm{pH}$ were selected for the simulated soil solution so that the variation of $\mathrm{pH}$ effect on corrosion can be studied. Based on research experience and pretrial, $\mathrm{pH}$ of 3.0 would accelerate the corrosion sufficiently to have significant effect on the mechanical properties of the metal within the project period. With the $\mathrm{pH}$ of natural soil being 8.0, a middle value of $\mathrm{pH}$ of 5.5 was selected.

Different values of $\mathrm{pH}$ were achieved by adding sulfuric acid and maintained the same during the whole test period. It may be noted that the added sulfuric acid may react with the chemicals in the solution but this reaction would happen in exactly the same manner as with the soluble chemicals in natural soil $[30,31]$. The point is that $\mathrm{pH}$ values of all solution were maintained the same and used as the measurement for the solution.

3.2. Test Variables. As discussed in the instruction, of many factors that affect corrosion of metals in soil and its effect on mechanical property, the chemical compositions of soil and metal are the most influential. In this study, the chemical composition of the soil was represented by $\mathrm{pH}$ and that of metal by grade. Therefore, the $\mathrm{pH}$ values of the soil solution and the type of metal were selected as the main testing variables as well as their change with time. Three values of $\mathrm{pH}$ were selected for soil solution as discussed above, which are 8.0, 5.5, and 3.0. Two types of metal were selected for corrosion test and its effects on mechanical properties which are carbon steel and grey cast iron. To obtain the variation of corrosion and its effect on mechanical properties of metals over time, three points of time were selected which are 90,180, and 270 days (or 3, 6, and 9 months), respectively,in addition to initial time, that is, before corrosion. Thus, there are four points in time in total. These times were selected based on the literature review and research experience to ensure the measurable corrosion and significant property change of mechanical properties of the specimens (e.g., [5, 32]).

For statistical studies, three duplicates were made for each specimen with the designated test variables. Therefore, the total number of test specimens is 3 ( $\mathrm{pH}$ values) $\times 2$ (two types of metal $) \times 2$ (properties $) \times 4$ (time points $) \times 3$ (duplicates $)=$ 144.

The measurement of the test includes (i) corrosion current; (ii) weight loss; (iii) tensile strength; and (iv) fracture toughness. Corrosion current was measured every day in the first week of the test and then weekly until the end of tests. Other three parameters were measured at initial point and three designated points of time, giving four measurements over time.

3.3. Test Setup and Procedure. Immersion corrosion test was conducted according to ASTM G31-2012a Standard Guide for Laboratory Immersion Corrosion Testing of Metals [34] in room temperature with soil solutions of three $\mathrm{pH}$ values

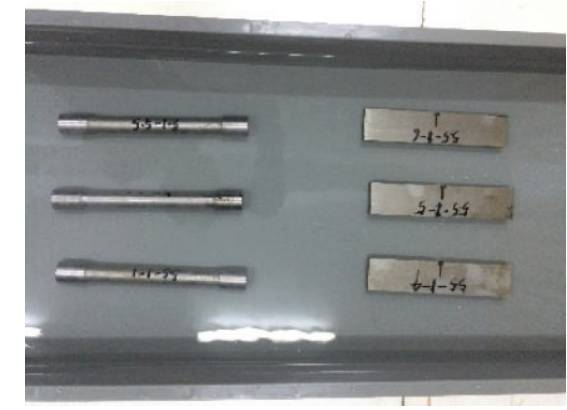

FIGURE 2: Specimens immersed in soil solution.

(3.0, 5.5, and 8.0) for a duration of three time periods of 90,180 , and 270 days. The specimens made of Q235 steel and HT200 cast iron were washed using 50\% acetone. They were then dried and placed in the containers of designated soil solutions. In each container, 6 specimens, 2 for mechanical property (tensile and fracture) and 3 duplicates, were immersed in the solution as shown in Figure 2. In total, there are 18 containers representing different $\mathrm{pH}$ values (3.0, 5.5, and 8.0) and materials (cast iron and steel). During immersion time, $\mathrm{pH}$ values in different containers were measured using a $\mathrm{pH}$ meter and controlled by adding sulfuric acid. Corrosion tests in all 18 containers were run in parallel.

To monitor the corrosion behavior wires were welded on two specimens of each type (labeled $1 \#$ for tensile specimen and $4 \#$ for toughness specimen) in each container and corrosion currents of the specimens were measured using an ampere meter. At each point of three designated times, that is, 90, 180, and 270 days, specimens were taken out of the solution for measurement of weight loss, tensile strength, and fracture toughness for three $\mathrm{pH}$ values and both steel and cast iron. Weight loss of the specimens was measured according to ASTMG31-12a. Tensile strength was tested on WAW-1000 material testing system as shown in Figure 3(a). Fracture toughness was tested on MTS landmark testing system as shown in Figure 3(b). Both tensile and fracture toughness tests were carried out by laboratory technicians to ensure the quality of the test results.

\section{Test Results and Analysis}

4.1. Corrosion Current. Corrosion current has long been used as a major indicator for corrosion behavior of metals [4, 12$15,35]$. In this study, corrosion currents were monitored over the whole test period and recorded using an ampere meter as shown in Figure 4. The results of corrosion currents are presented in Figures 5 and 6 for steel and cast iron specimens, respectively. It can be seen from the figures that the corrosion currents are in general very scattered. This is not unexpected due to the random occurrence and growth of corrosion. It may also be attributed to the accuracy in measuring the current due to aggressive environments.

Figures 5 and 6 indicate that although each point of measure corrosion current is scattered, the general trend of corrosion currents is clear, which is decreasing with the 


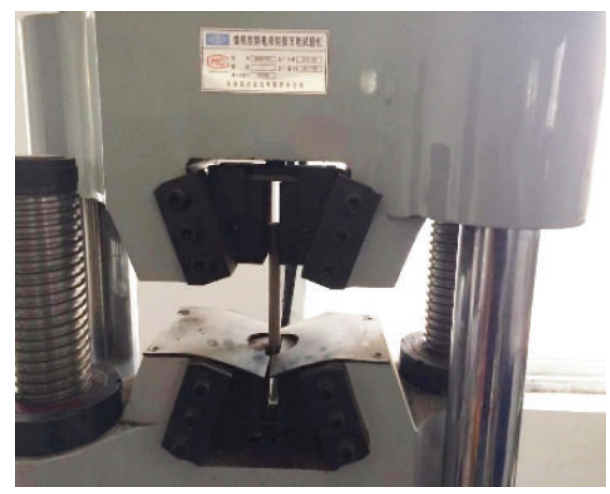

(a)

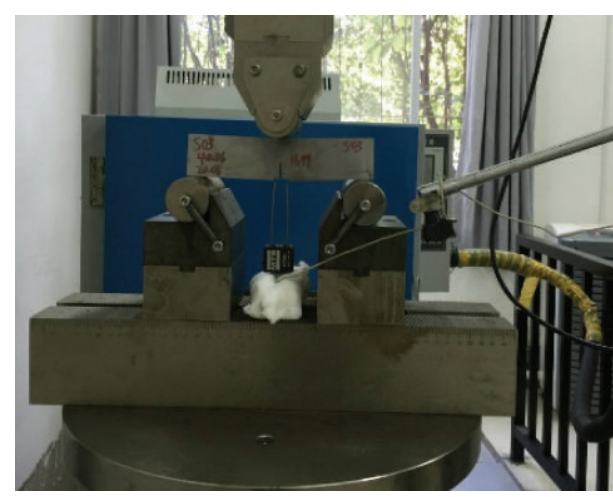

(b)

FIgure 3: Test facilities: tensile (a) and fracture toughness (b) testing systems.

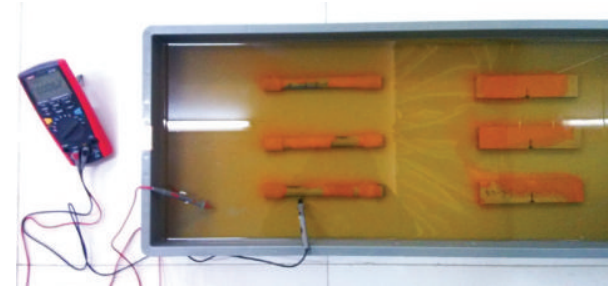

FIGURE 4: Monitoring of corrosion current.

exposure time. This means that current rate is high at the beginning of the corrosion and decreases over time. As it is well known, corrosion is an electrochemical process. The acidic environment can initiate the corrosion but the progress of corrosion needs the supply of oxygen which is not readily available to keep the high corrosion rate. These results are consistent with other results reported in the literature as well as research experience [5].

Figures 5 and 6 also show that corrosion currents are generally larger for more acidic solution, that is, smaller $\mathrm{pH}$ value, in particular at the beginning. This is again consistent with results published in literature. For example, a study by Panossian et al. [15] shows that the smaller $\mathrm{pH}$ is, the larger corrosion currents are, indicating that acid can induce more corrosion. Though corrosion currents in solution with smaller $\mathrm{pH}$ are comparatively larger, the decreasing rates of corrosion currents (i.e., the slope of the curve) are irregular, exhibiting the randomness of corrosion behavior. Corrosion currents in solutions with $\mathrm{pH}$ of 8.0 and 5.5 have the largest and the smallest decreasing rates, respectively. In general, the differences in variation rates of corrosion current (the slope of the curve) for different $\mathrm{pH}$ are $26.6 \%$ between 3.0 and 5.5 and $-25.0 \%$ between 5.5 and 8.0 .

The comparison of Figures 5 and 6 also shows that corrosion of cast iron is slightly faster than steel. As suggested by Dean Jr. and Grab [9], one of the reasons for this can be that a higher carbon content in metal can incur a larger corrosion rate.

4.2. Weight Loss. Before the test, all specimens were cleaned and weighed. After immersion, specimens were taken out at three designated points of time, that is, 90, 180, and 270 days, respectively. Figure 7 shows the progress of corrosion activity in terms of change in color, rust accumulation, and distribution. Then they were dried, cleaned, and weighed again. Weight loss was calculated as reduction in weight of each specimen before and after immersion. Weight loss is normalized by surface area and expressed in $\mathrm{g} \cdot \mathrm{m}^{-2}$ to eliminate the influence of differences in shapes and exposure areas. Figure 8 shows the results of weight loss for steel and cast iron specimens, respectively, where each point is the average of three measurements of weight. The range of coefficients of variation of weight loss at each point is from 0.09 to 0.22 over the test period.

Figure 8 shows that the weight decreases with time almost linearly for both steel and cast iron specimens which is different from the results of corrosion current (which is nonlinear over time). The reason could be that the weight loss represents the cumulative effect of corrosion which is more gradual whilst the corrosion current represents the instantaneous rate of corrosion which is more fluctuated. It can be seen that weight loss is larger with smaller $\mathrm{pH}$ value, that is, $\mathrm{pH}=3.0$. This is consistent with the results of corrosion current. It can be also seen from Figure 8 that the trend of weight loss of both steel and cast iron specimens is almost the same although the weight loss of cast iron specimens due to corrosion is slightly larger. Again this is consistent with the results of corrosion current. As can be seen from the figure, there is not much difference in weight loss when $\mathrm{pH}$ values are between 5.5 and 8.0 in particular for cast iron.

4.3. Yield Strength Reduction. The main objective of this research is to investigate the effect of corrosion on mechanical properties of metals as represented by tensile strength and fracture toughness. For this purpose, specimens were taken out of the immersion after 90, 180, and 270 days of corrosion, respectively. Then they were cleaned and loaded to failure in tension on the testing machine in Figure 3(a). The results of tensile tests are shown in Figure 9, where each point represents an average of three testing results. The range of coefficients of variation of tensile strength reduction at each point is from 0.11 to 0.19 over the test period. 


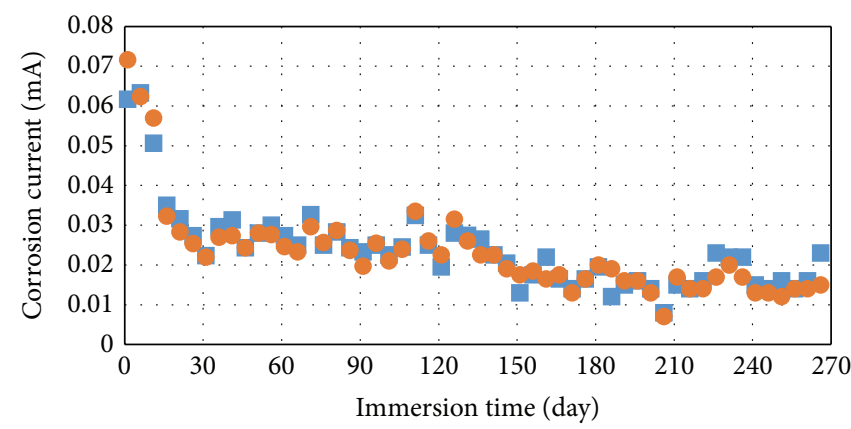

Specimen 1 - Specimen 4

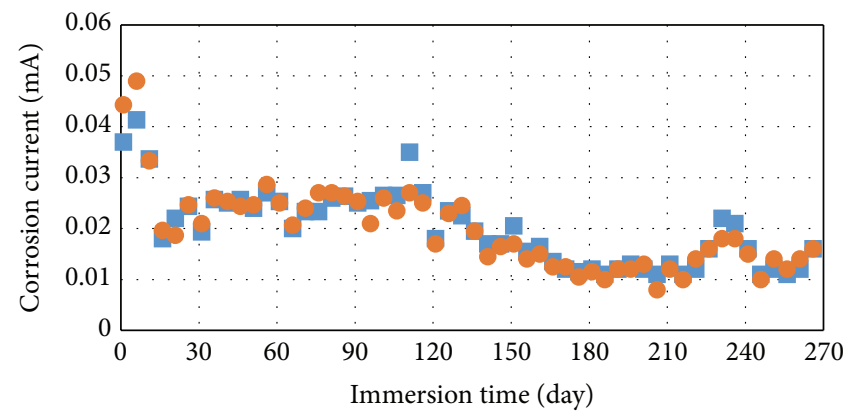

- Specimen 1

- Specimen 4

(a) $\mathrm{pH}=3.0$

(b) $\mathrm{pH}=5.5$

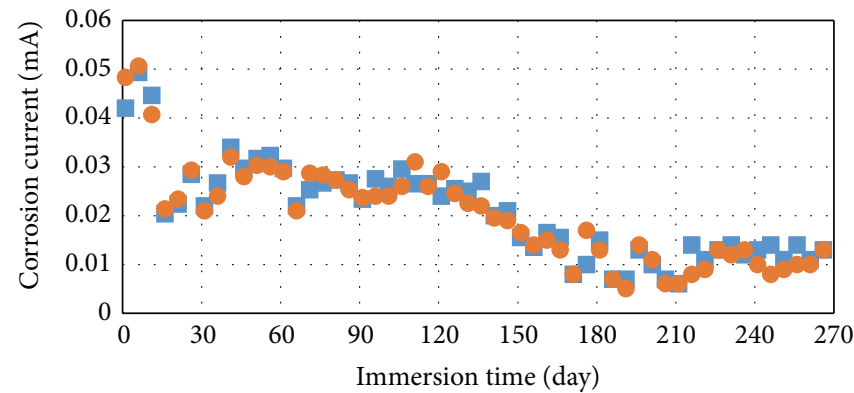

Specimen 1

- Specimen 4

(c) $\mathrm{pH}=8.0$

FIGURE 5: Corrosion current in steel specimens in solutions of different pH values.

From Figure 9, it can be seen that the tensile strength decreases with time due to corrosion. This is the case for both steel and cast iron materials. The results of Figure 9 provide good evidence that corrosion does affect the mechanical property of metals. This is mainly due to the fact that corrosion penetrates the surface of the specimens, destroying the compactness of the specimen surface. It can be seen in Figure 7 that surfaces of all corroded specimens are rougher and more porous than intact metals, which makes it easier for corrosive agents or other elements, for example, $\mathrm{O}$ and $\mathrm{Cl}$, to ingress into the metal. The ingress of corrosive agents and/or elements can alter the chemical composition of metal via chemical reactions of these agents and elements. It can also change the morphology or microstructure of the metal. As is known, chemical composition and morphology are main factors that determine the mechanical property of metals. As a result, the mechanical property of the metal changed.

Table 4 shows the corrosion induced deterioration of mechanical properties of steel and cast iron at three time periods of test. It can be seen that the reduction of tensile strength increases with the exposure time for both steel and cast iron. These results are in agreement with the results of weight loss which shows a linear increase with time (Figure 8) as discussed above. Also seen from the table is the fact that the reduction of tensile strength of cast iron is larger than that of steel. This is again consistent with the results of both corrosion current and weight loss, indicating that high carbon content in metal may not only lead to more corrosion [9] but also have more effect on tensile strength. Table 4 also shows that in the first period of exposure the reduction of tensile strength is larger for more acidic environment (i.e., $\mathrm{pH}=3.0$ ) but later in the third period the reduction of tensile strength is larger for less acidic environment (i.e., $\mathrm{pH}$ $=8.0$ ), indicating that high acidity may accelerate corrosion of metal but may not necessarily accelerate the corrosion effect on its mechanical properties which is determined by its chemical position, morphology, and microstructure as discussed previously.

4.4. Fracture Toughness Reduction. Fracture toughness of metals is determined by three-point bending test as shown in Figure 3(b). From this test, the fracture toughness can be calculated as follows:

$$
K_{(i)}=\left[\frac{P_{i} S}{\left(B B_{N}\right)^{1 / 2} W^{3 / 2}}\right] f\left(\frac{a_{i}}{W}\right),
$$




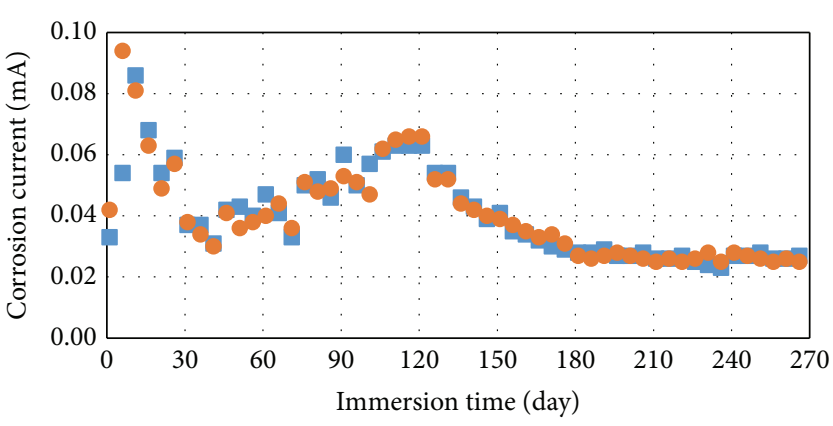

- Specimen 1

- Specimen 4

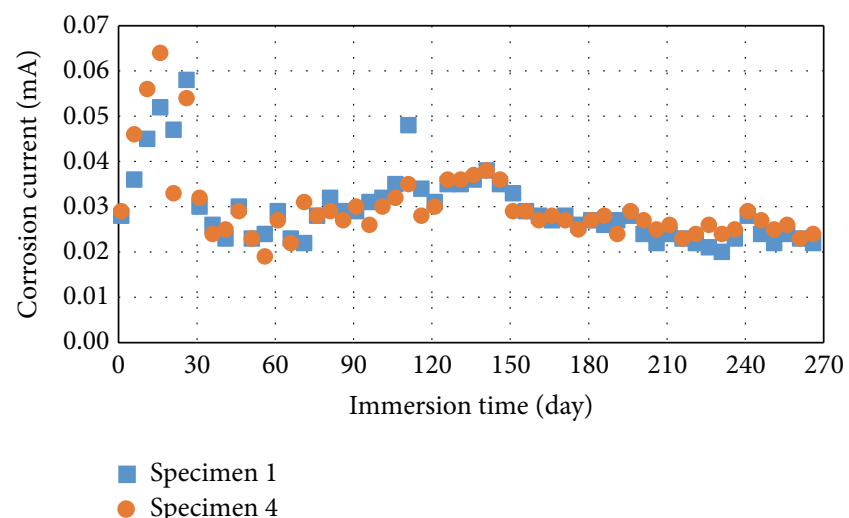

(b) $\mathrm{pH}=5.5$
Specimen 4

(a) $\mathrm{pH}=3.0$

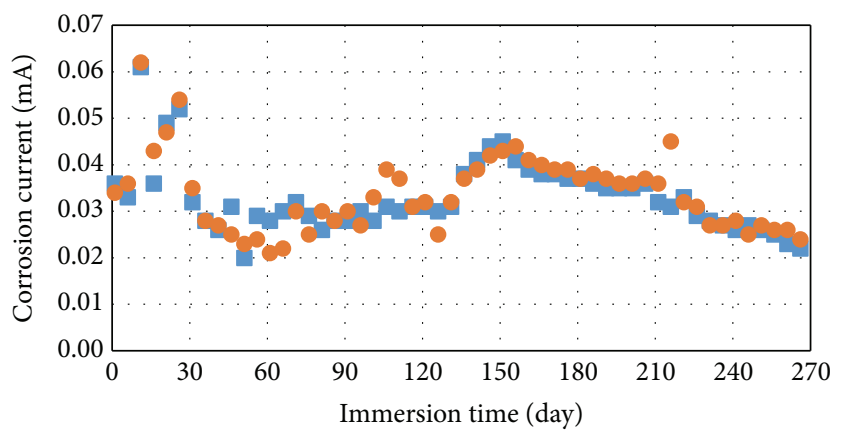

Specimen 1

Specimen 4

(c) $\mathrm{pH}=8.0$

FIGURE 6: Corrosion currents in cast iron specimens in solutions of different $\mathrm{pH}$ values.

where

$$
f\left(\frac{a_{i}}{W}\right)=\frac{3\left(a_{i} / W\right)^{1 / 2}\left[1.99-\left(a_{i} / W\right)\left(1-a_{i} / W\right) \times\left(2.15-3.93\left(a_{i} / W\right)+2.7\left(a_{i} / W\right)^{2}\right)\right]}{2\left(1+2 a_{i} / W\right)\left(1-a_{i} / W\right)^{3 / 2}}
$$

and $K_{(i)}$ is the calculated $K$ for the bend specimen at load $P_{i}$, $S$ is the support span, $B$ and $B_{N}$ are the width and net width of specimen, respectively, $a_{i}$ is the current crack length, and $W$ is the height of the specimen (see Figure 1(b)). In this study, the fracture toughness values, that is, $K_{\mathrm{IC}}$, were determined directly from the testing machine as outputs, using the builtin program.

The results of fracture toughness reduction are shown in Figure 10, where again each point represents an average of three testing results. The range of coefficients of variation of fracture toughness reduction at each point is from 0.12 to 0.17 over the test period. It can be seen from the figure that the fracture toughness also decreases with time due to corrosion. This is true for both steel and cast iron materials. The results of Figure 10 again provide the evidence that corrosion does affect the mechanical property of metals for the same reason as explained for the tensile strength. In addition, it can be seen in Figure 7 that the penetration of corrosion into the metal is not evenly distributed. In most cases, the locations that are damaged incur the most corrosion, forming localized corrosion pits. This is true especially when there is a precrack where the corrosion is the most severe, leading to the extension of the crack of the specimen. As it is known, the crack extension is the most affecting factor for the determination of fracture toughness [21].

In addition, from Table 4 it can be seen that the corrosion induced deterioration of fracture toughness is remarkably larger than that of tensile strength under the same conditions. This indicates that corrosion has larger effect on fracture toughness than tensile strength of the metal. The reason can be that, as explained above, corrosion pits extend the existing defects of the metal which reduce the fracture toughness. Also the reduction of fracture toughness for cast iron is almost twice that of steel. The results of all four measurements 


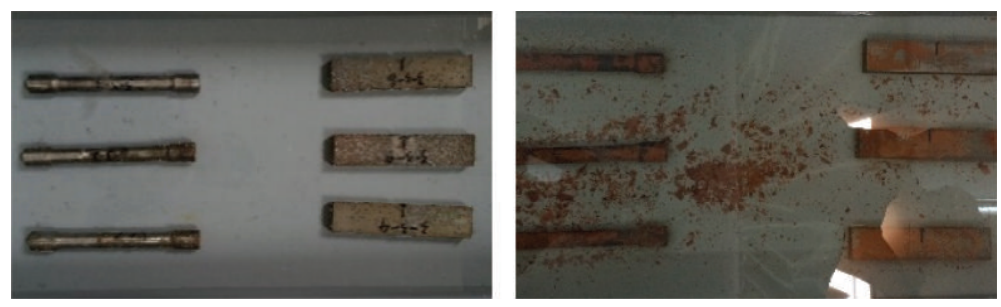

(a) For specimens at 6 days (steel left, cast iron right)
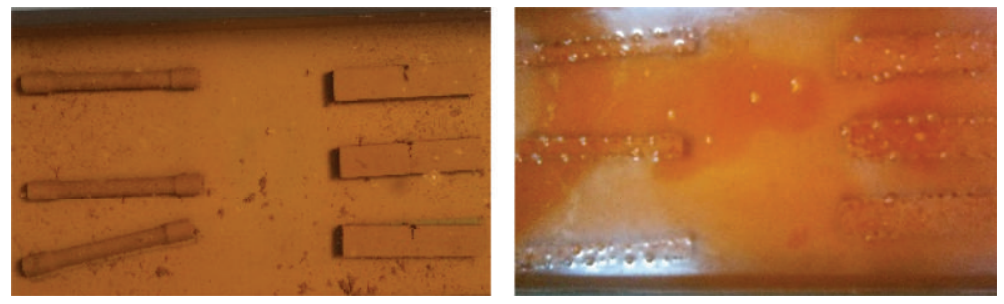

(b) For specimens at 30 days (steel left, cast iron right)
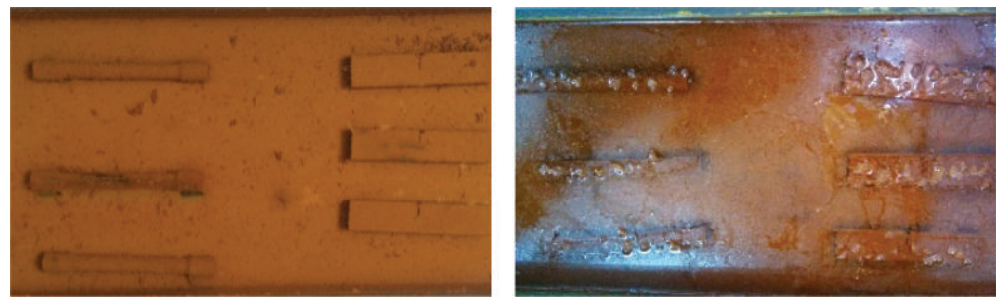

(c) For specimens at 90 days (steel left, cast iron right)

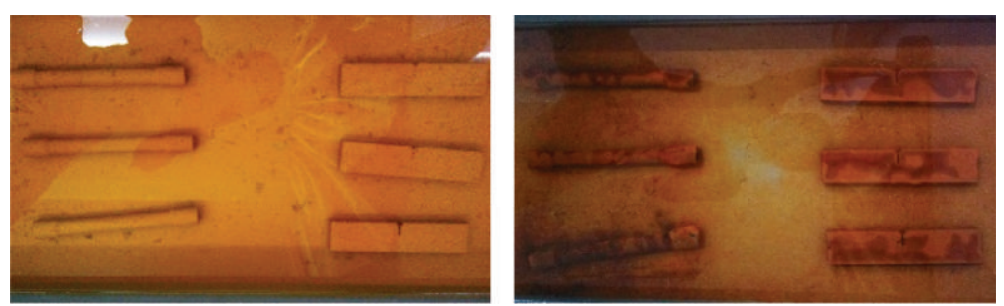

(d) For specimens at 180 days (steel left, cast iron right)
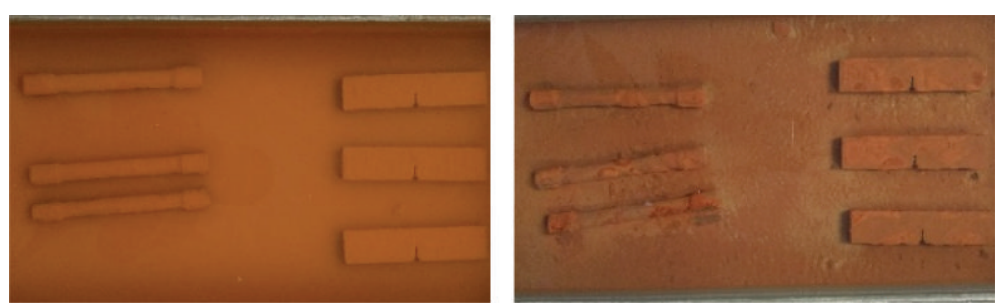

(e) For specimens at 270 days (steel left, cast iron right)

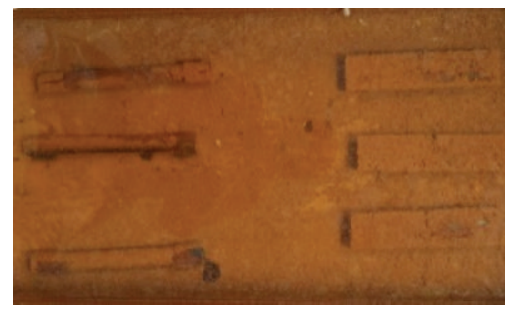

(f) Details of a very corroded specimen covered with rusts

FIGURE 7: Photos of corroded specimens at different exposure periods. 


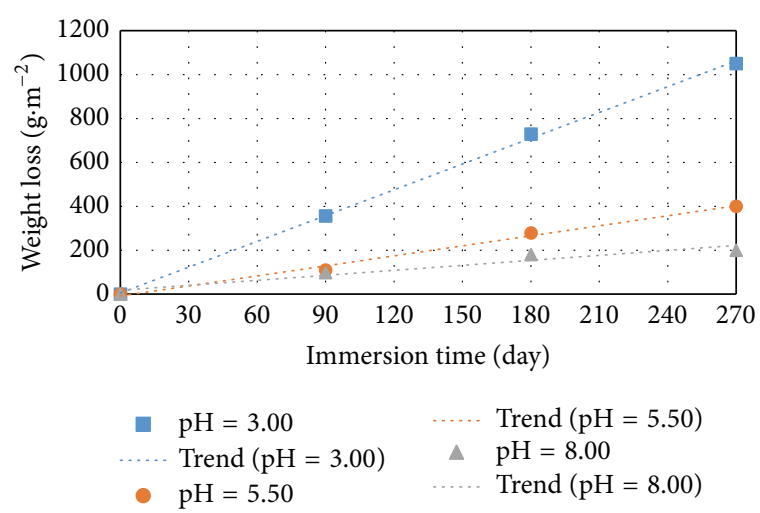

(a) For steel

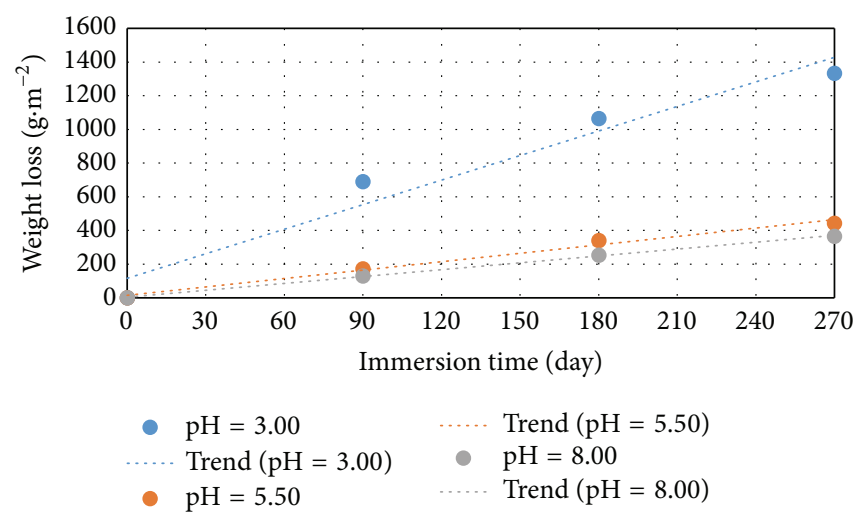

(b) For cast iron

FIGURE 8: Weight loss of specimen.

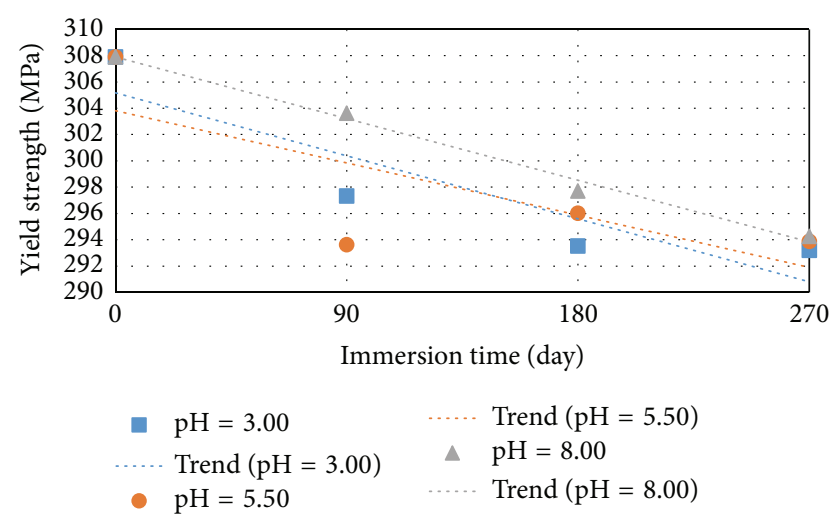

(a) For steel

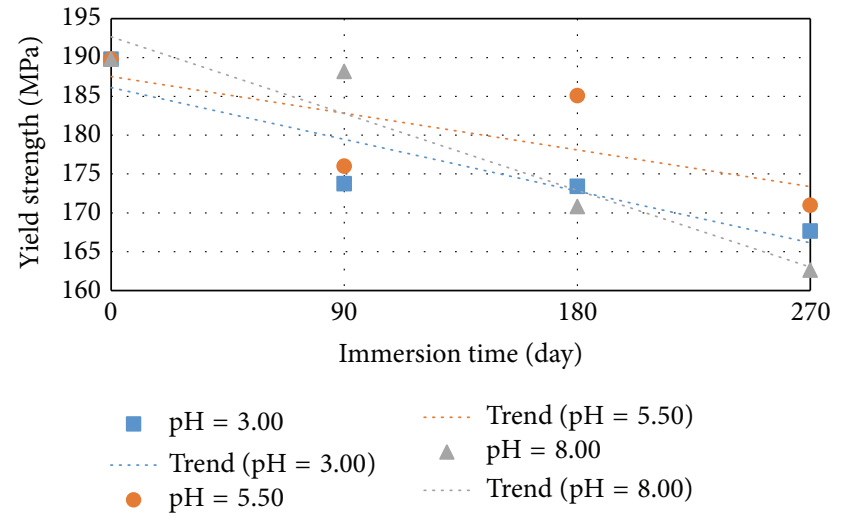

(b) For cast iron

FIGURE 9: Tensile strength reduction of specimen.

(corrosion current, weight loss, tensile strength, and fracture toughness) suggest that high carbon content in metal can not only lead to more corrosion but also incur larger effect on mechanical properties.

\section{Observation and Discussion}

From the tests and test results further observation and discussion can be made. Photos of corroded specimens can provide some insight into the behavior of corrosion in different environments and states. From Figures 5 and 6, it can be seen that corrosion current is the highest at the onset of corrosion but from Figure $7(\mathrm{a})$ it can be seen that little visible change can be seen in terms of change of color (rust) of specimens although corrosion currents were at their peaks. This again indicates that the corrosion current measures instantaneous corrosion rate not the cumulative corrosion. At this stage, corrosive agents penetrated the oxidation film but little amount of corrosion was produced. This suggests that corrosion rate of the specimens is high but actual corrosion, in terms of products, that is, rusts, is not accumulated. The corrosion reaction can be expressed as follows (e.g., [35]): (a) Anodic reaction

$$
\mathrm{Fe} \longrightarrow \mathrm{Fe}^{2+}+2 \mathrm{e}^{-}
$$

(b) Cathodic reaction

$$
2 \mathrm{H}^{+}+2 \mathrm{e}^{-} \longrightarrow \mathrm{H}_{2}
$$

After 6 days of immersion, the corrosion currents dropped sharply indicating that the corrosion rate is reduced but corrosion itself continues. This is demonstrated in Figure 7(a), where the solution turned into a brown color especially for the solution with $\mathrm{pH}=5.5$. The corrosion reactions at his stage can be expressed as follows [35]:

$$
\begin{aligned}
4 \mathrm{Fe}^{2+}+\mathrm{O}_{2}+4 \mathrm{H}^{+} & =4 \mathrm{Fe}^{3+}+2 \mathrm{H}_{2} \mathrm{O} \\
2 \mathrm{Fe}+\mathrm{O}_{2}+2 \mathrm{H}_{2} \mathrm{O} & =2 \mathrm{Fe}(\mathrm{OH})_{2} \\
4 \mathrm{Fe}(\mathrm{OH})_{2}+\mathrm{O}_{2}+2 \mathrm{H}_{2} \mathrm{O} & =4 \mathrm{Fe}(\mathrm{OH})_{3}
\end{aligned}
$$

With the increase of corrosion, hydrogen bubbles showed up in particular in more acidic solution, for example, $\mathrm{pH}=3.0$, which can be explained by (6). 


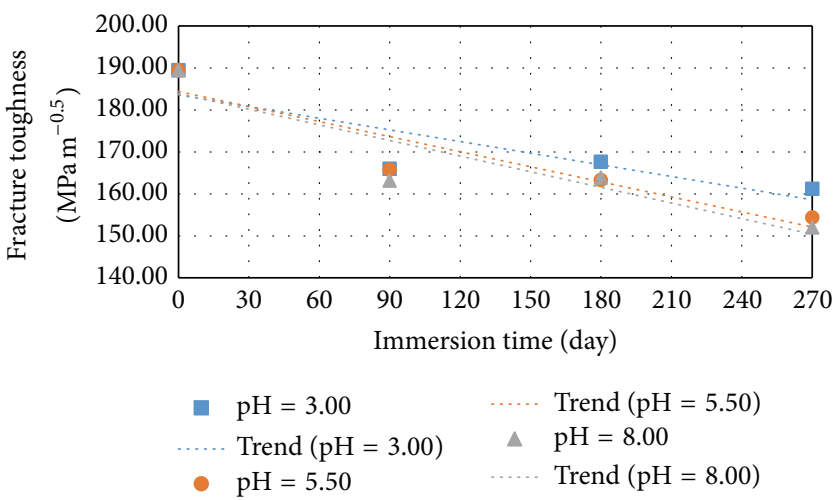

(a) For steel

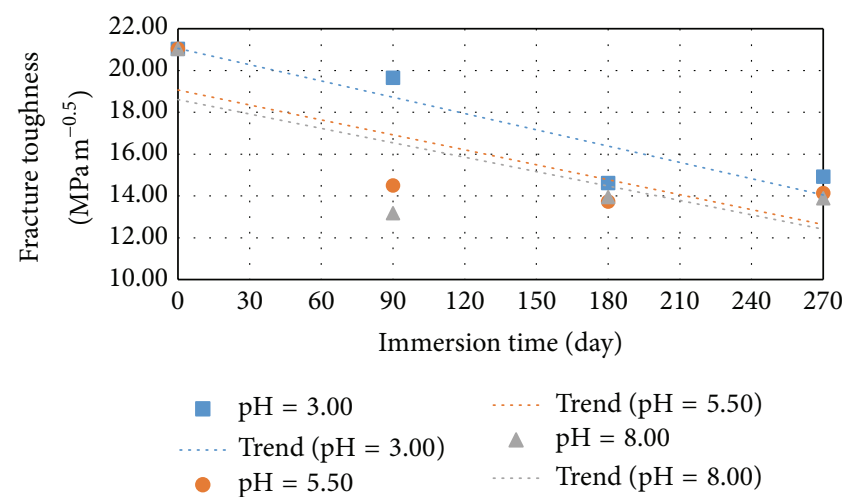

(b) For cast iron

FIGURE 10: Fracture toughness reduction of specimen.

TABLE 4: Reduction of mechanical property (\%).

(a) For steel

\begin{tabular}{lccc}
\hline Time period (day) & $\mathrm{pH}$ & Tensile strength & Fracture toughness \\
\hline \multirow{3}{*}{90} & 3.0 & 3.43 & 9.29 \\
& 5.5 & 2.63 & 7.51 \\
& 8.0 & 1.39 & 6.35 \\
\multirow{2}{*}{180} & 3.0 & 4.66 & 11.51 \\
& 5.5 & 3.86 & 13.80 \\
& 8.0 & 3.31 & 13.51 \\
\hline \multirow{2}{*}{270} & 3.0 & 4.77 & 14.93 \\
& 5.5 & 4.56 & 18.50 \\
& 8.0 & 4.43 & 19.77 \\
\hline
\end{tabular}

(b) For cast iron

\begin{tabular}{lccc}
\hline Time period (day) & $\mathrm{pH}$ & Tensile strength & Fracture toughness \\
\hline \multirow{3}{*}{90} & 3.0 & 8.45 & 6.56 \\
& 5.5 & 3.24 & 2.05 \\
& 8.0 & 0.84 & 1.38 \\
\hline \multirow{3}{*}{180} & 3.0 & 8.62 & 20.36 \\
& 5.5 & 4.32 & 18.63 \\
& 8.0 & 9.98 & 33.67 \\
\hline \multirow{2}{*}{270} & 3.0 & 11.64 & 29.05 \\
& 5.5 & 9.89 & 32.79 \\
& 8.0 & 14.31 & 33.99
\end{tabular}

It was also observed that corrosion in different conditions was of different forms. Corrosion pits were formed after surface oxidation film was penetrated, which was the case for all three scenarios of $\mathrm{pH}$ values. However, corrosion pits on specimens in more acidic solution, for example, $\mathrm{pH}$ $=3.0$, were fewer and more evenly distributed than those on specimens in less acidic solutions, for example, larger $\mathrm{pH}$ values. This is shown in Figure $7(\mathrm{~b})$ where, at 30 days, localized corrosion pits were more obvious and corrosion products began to become flakes. Deposits of corrosion products in two solutions with lower $\mathrm{pH}$ values (3.0 and 5.5) were in larger amount.
Figure 7(c) shows that specimens were further corroded and that corrosion products fell down to the bottom of the containers and covered up the surface of the specimens. The latter would prevent specimens from further corrosion so that the corrosion currents in specimens for all solutions reach the lowest values after 90 days.

It has also been observed from Figures 9 and 10 that the reduction of mechanical properties, both tensile strength and fracture toughness, does not follow the same trend as corrosion current and weight loss. That is, smaller value of $\mathrm{pH}$, that is, more acidic solution, does not result in larger reduction of mechanical properties for both tensile strength and fracture toughness. This may be because whilst the $\mathrm{pH}$ can accelerate corrosion of metal, it may neither accelerate the reaction of corrosive agents with chemical elements of metal nor accelerate the change of microstructure of the metal. In other words, the effect of corrosion on mechanical properties of metals may not be in the same proportion as that of $\mathrm{pH}$ on corrosion, further indicating the randomness of both corrosion behavior and its effect on mechanical property of the metal. Also the reduction of mechanical properties is more scattered with respect to $\mathrm{pH}$ than corrosion current and weight loss. The precision of measurement can also contribute to the degree of the disperse. Obviously more experiments are needed to produce sufficient and quality data for developing models for corrosion induced deterioration of mechanical properties of metals.

For practical application of corrosion effect on mechanical properties of metal, it is desirable to develop a relationship between measurable parameters of corrosion, for example, weight loss, and the reduction of mechanical properties, for example, tensile strength and fracture toughness. This has been attempted in this study. Since the analysis of results presented in the previous section suggests that weight loss can be a better measure of corrosion than corrosion current, it is used in developing the relationship. Also ideally more data points (than four) can produce better correlation of this relation but time and resources are always the constraints. Literature and research experience (e.g., [32]) suggest that three data points are minimum. Figures 11 and 12 show the variation of tensile strength and fracture toughness with 


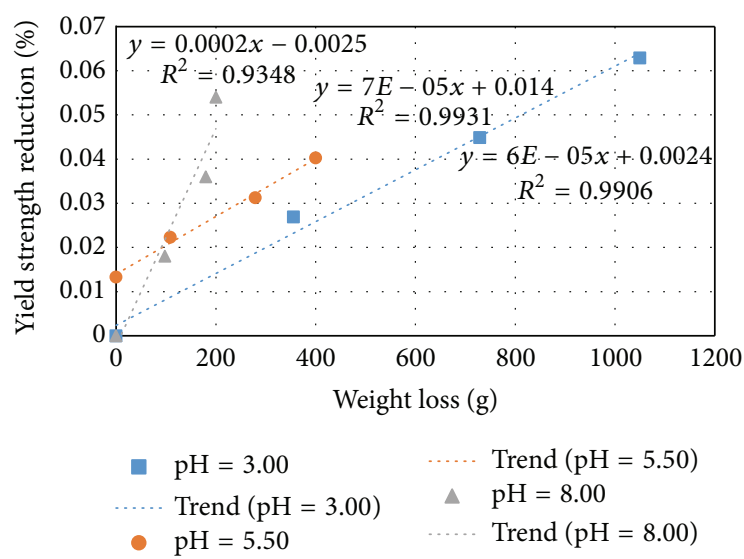

(a) For steel

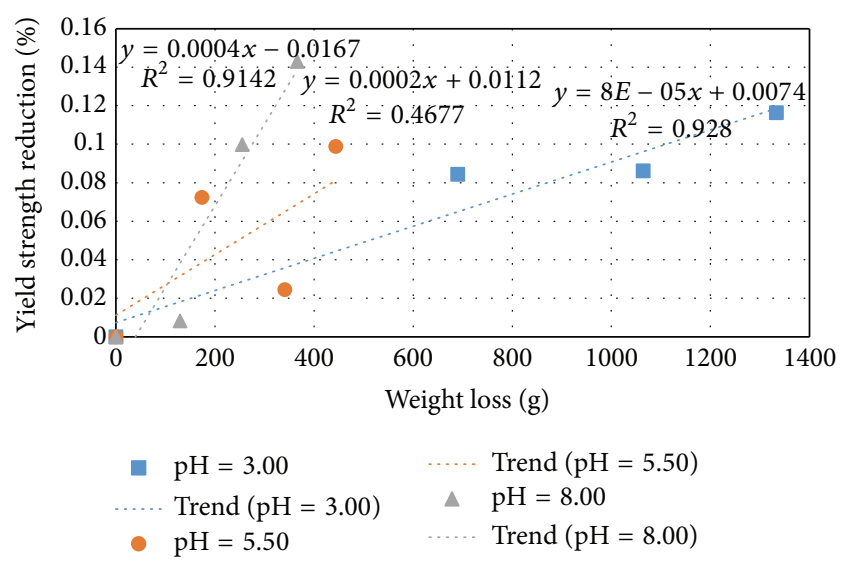

(b) For cast iron

FIgURE 11: Tensile strength reduction with weight loss.

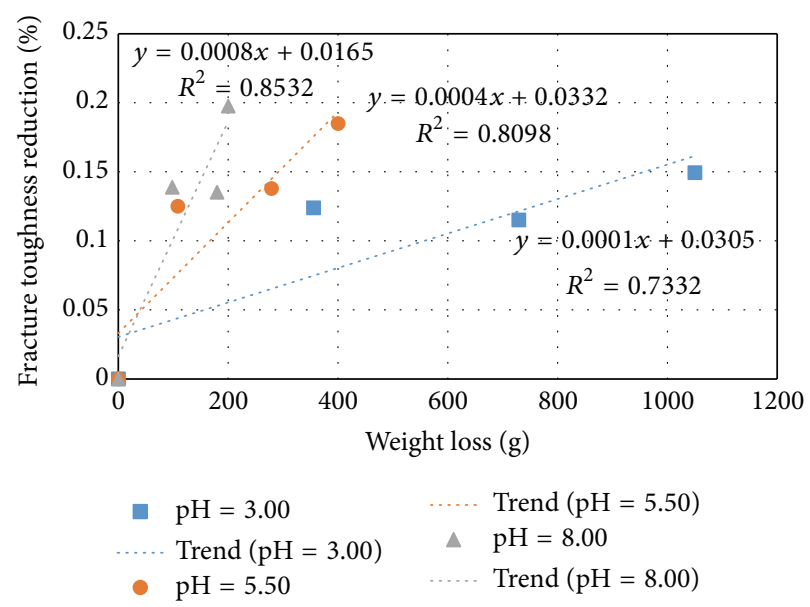

(a) For steel

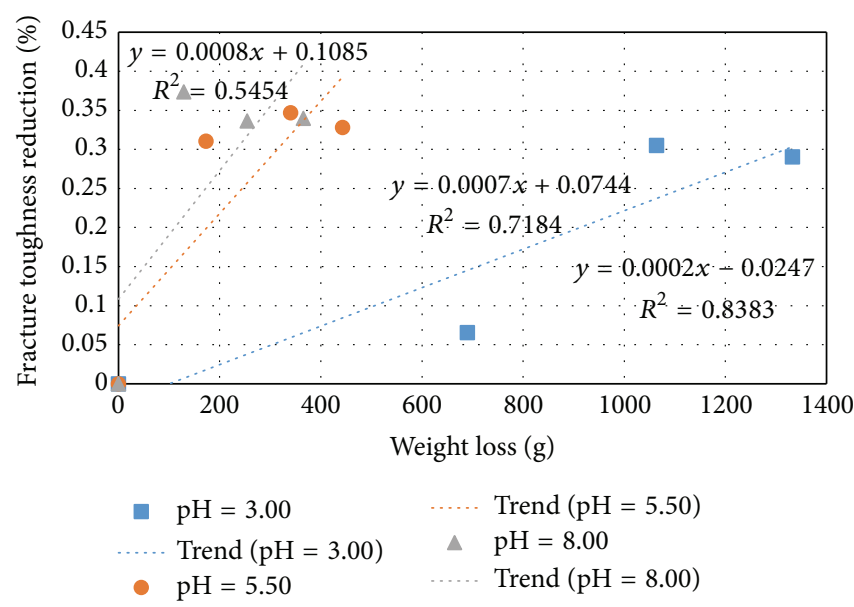

(b) For cast iron

FIGURE 12: Fracture toughness reduction with weight loss.

weight loss for both steel and cast iron specimens under three tested environments. As can be seen from the figures, the reduction of both tensile strength and fracture toughness is by and large in linear relation with weight loss. Though the lower $\mathrm{pH}$ values contribute to greater weight losses, mechanical properties are more sensitive to weight loss in higher $\mathrm{pH}$ values, that is, steeper trend lines as shown in Figures 11 and 12. In practice, $\mathrm{pH}$ values of soil cannot be lower than 5 . As such results of this study for $\mathrm{pH}$ lower than 5 can be closer to reality and hence can be of more practical use.

It needs to be noted that the test results presented in the paper are one step towards establishing understanding and knowledge on corrosion effect on mechanical properties of metals. The significance of these results lies more in their trend more qualitatively than quantitatively. It is acknowledged that more tests are necessary to produce larger pool of data for sensible quantitative analysis, based on which we develop theories and models for corrosion induced deterioration of mechanical properties of metals. This work is being continued by corresponding author's research team with more test specimens under different testing variables and environments, such as real soil environment. More results will be submitted for publication once they are produced, processed, and analyzed.

\section{Conclusion}

A comprehensive test program has been presented in the paper to investigate the effect of corrosion on mechanical properties of buried metal pipes. The corrosion of two types of widely used metals, that is, cast iron and steel, and its effect on their mechanical properties have been observed, monitored, and evaluated in three different environments as represented by $\mathrm{pH}$ values. From the analysis of the test results, a relationship between corrosion and deterioration of mechanical property of metals has been developed. It has been found that the more acidic the environment is, the more corrosion of metal occurs and that grey cast iron corrodes more than carbon steel under the same environment. It has also been found that the corrosion reduces both the tensile 
strength and fracture toughness of the metal and the latter reduced more than the former. It can be concluded that the results presented in the paper can contribute to the body of knowledge of corrosion behavior and its effect on mechanical properties of metals in soil environment. This knowledge can enable more accurate prediction of failures of metal pipes.

\section{Competing Interests}

The authors declare that they have no competing interests.

\section{Acknowledgments}

Financial support from Natural Science Foundation of Hubei Province of China under 2015CFB510, Fundamental Research Funds by Wuhan University of Technology of China under 2015IVA012, and Australian Research Council under DP140101547 and LP150100413 is gratefully acknowledged.

\section{References}

[1] Y. Li, B. Jiang, H. Zhao, and C. Tao, "Experimental study on internal corrosion of grey cast iron pipeline in water distribution," Journal of Chemical Information and Modeling, vol. 53, article 160, 1989.

[2] J. M. Makar, "Preliminary analysis of failures in grey cast iron water pipes," Engineering Failure Analysis, vol. 7, no. 1, pp. 4353, 2000.

[3] National Water Commission Australia, National performance report 2009-10, http://archive.nwc.gov.au/__data/assets/pdf_ file/0015/11265/NPR_urban.pdf.

[4] B. Rajani, S. McDonald, and G. Felio, "Water mains break data on different pipe materials for 1992 and 1993," Report A-7019.1, National Research Council of Canada, Ottawa, Canada, 1995.

[5] H. Mohebbi and C. Q. Li, "Experimental investigation on corrosion of cast iron pipes," International Journal of Corrosion, vol. 2011, Article ID 506501, 17 pages, 2011.

[6] R. A. de Sena, I. N. Bastos, and G. M. Platt, "Theoretical and experimental aspects of the corrosivity of simulated soil solutions," ISRN Chemical Engineering, vol. 2012, Article ID 103715, 6 pages, 2012.

[7] C. Goulter, "An analysis of pipe breakage in urban water distribution networks," Canadian Journal of Civil Engineering, vol. 12, no. 2, pp. 286-293, 1985.

[8] M. L. Doleac, S. L. Lackey, and G. N. Bratton, "Prediction of time-to failure for buried cast iron pipe," in Proceedings of the Annual Conference of the American Water Works Association (AWWA '80), pp. 31-38, Denver, Colo, USA, 1980.

[9] S. W. Dean Jr. and G. D. Grab, "Corrosion of carbon steel by concentrated sulfuric acid," Materials Performance, vol. 24, no. 6, pp. 21-25, 1985.

[10] D. K. O'Day, R. Weiss, S. Chiavari, and D. Blair, Water Main Evaluation for Rehabilitation/Replacement, American Water Works Association Research Foundation, Denver, Colo, USA, 1986.

[11] M. Randall-Smith, A. Russell, and R. Oliphant, Guidance Manual for the Structural Condition Assessment of the Trunk Mains, Water Research Centre, Swindon, UK, 1992.
[12] G. J. Kirmeyer, W. Richards, and C. D. Smith, An Assessment of Water Distribution Systems and Associated Research Needs, AWWA, 1994.

[13] L. Camarinopoulos, A. Chatzoulis, S. Frontistou-Yannas, and V. Kallidromitis, "Assessment of the time-dependent structural reliability of buried water mains," Reliability Engineering and System Safety, vol. 65, no. 1, pp. 41-53, 1999.

[14] R. Sadiq, B. Rajani, and Y. Kleiner, "Probabilistic risk analysis of corrosion associated failures in cast iron water mains," Reliability Engineering and System Safety, vol. 86, no. 1, pp. 1-10, 2004.

[15] Z. Panossian, N. L. de Almeida, R. M. F. de Sousa, G. de Souza Pimenta, and R. B. S. Marques, "Corrosion of carbon steel pipes and tanks by concentrated sulfuric acid: a review," Corrosion Science, vol. 58, pp. 1-11, 2012.

[16] L. A. Rossman, R. A. Brown, P. C. Singer, and J. R. Nuckols, "DBP formation kinetics in a simulated distribution system," Water Research, vol. 35, no. 14, pp. 3483-3489, 2001.

[17] V. Chacker and J. D. Palmer, Eds., Effect of Soil Characteristic on Corrosion, ASTM Special Technical Publication, Ann Arbor, Mich, USA, 1989.

[18] T. M. Liu, Y. H. Wu, S. X. Luo, and C. Sun, "Effect of soil compositions on the electrochemical corrosion behavior of carbon steel in simulated soil solution. Einfluss der Erdbodenzusammensetzung auf das elektrochemische Verhalten von Kohlenstoffstählen in simulierten Erdbodenlösungen," Materialwissenschaft und Werkstofftechnik, vol. 41, no. 4, pp. 228-233, 2010.

[19] B. Rajani and Y. Kleiner, "Comprehensive review of structural deterioration of water mains: physically based models," Urban Water, vol. 3, no. 3, pp. 151-164, 2001.

[20] J. Li, R. Tang, J.-F. Liu, and J.-S. Liu, "The analysis of soil corrosion factors in long-distance oil pipeline," Equipment Manufacturing, no. 9, pp. 31-33, 2012.

[21] C. Q. Li and S. T. Yang, "Stress intensity factors for high aspect ratio semi-elliptical internal surface cracks in pipes," International Journal of Pressure Vessels and Piping, vol. 96-97, pp. 13-23, 2012.

[22] P. Marshall, The Residual Structural Properties of Cast Iron Pipes-Structural and Design Criteria for Linings for Water Mains, Water Industry Research, London, UK, 2001.

[23] S. K. Singh and A. K. Mukherjee, "Kinetics of mild steel corrosion in aqueous acetic acid solutions," Journal of Materials Science and Technology, vol. 26, no. 3, pp. 264-269, 2010.

[24] Y. H. Wu, T. M. Liu, S. X. Luo, and C. Sun, "Corrosion characteristics of Q235 steel in simulated Yingtan soil solutions," Materialwissenschaft und Werkstofftechnik, vol. 41, no. 3, pp. 142-146, 2010.

[25] ASTM E8M13, Standard Test Methods for Tension Testing of Metallic Materials, ASTM International, 2013.

[26] ASTM-E1820, Standard Test Method for Measurement of Fracture Toughness, ASTM International, 2013.

[27] Z. Zhao, Y. Lu, and G. Sun, "Experimental measuring fracture toughness of Q235 steel by J integral," Journal of Wuhan University of Technology, vol. 24, no. 4, pp. 111-112, 2002.

[28] D. Dong, X. Zhu, and X. Mei, "Abaqus Q235 simulation on fracture toughness of material Q235 based on flexibility determination method of Abaqus," Computer Aided Engineering, vol. 21, no. 4, pp. 4-6, 2012.

[29] M. Wasim, C. Q. Li, D. J. Robert, and M. Mahmoodian, "Experimental investigation of factors influencing external corrosion 
of buried pipes," in Proceedings of the 4th International Conference on Sustainability Construction Materials and Technologies (SCMT '16), Las Vegas, Nev, USA, August 2016.

[30] M. Yan, J. Wang, E. Han, and W. Ke, "Local environment under simulated disbonded coating on steel pipelines in soil solution," Corrosion Science, vol. 50, no. 5, pp. 1331-1339, 2008.

[31] Z. Y. Liu, X. G. Li, C. W. Du, and Y. F. Cheng, "Local additional potential model for effect of strain rate on SCC of pipeline steel in an acidic soil solution," Corrosion Science, vol. 51, no. 12, pp. 2863-2871, 2009.

[32] C. Q. Li, "Initiation of chloride-induced reinforcement corrosion in concrete structural members-experimentation," $A C I$ Structural Journal, vol. 98, no. 4, pp. 502-510, 2001.

[33] F. Long, W. Zheng, C. Chen, Z. Xu, and Q. Han, "Influence of temperature, $\mathrm{CO}_{2}$ partial pressure, flow rate and $\mathrm{pH}$ value on uniform corrosion rate of X65 pipeline steel," Corrosion and Protection, vol. 26, no. 7, pp. 290-294, 2005.

[34] ASTM G31-2012a, Standard Guide for Laboratory Immersion Corrosion Testing of Metals, ASTM International, 2012.

[35] L. L. Shreir, R. A. Jarman, and G. T. Burstein, Corrosion, Butterworth Heinemann, 2010. 

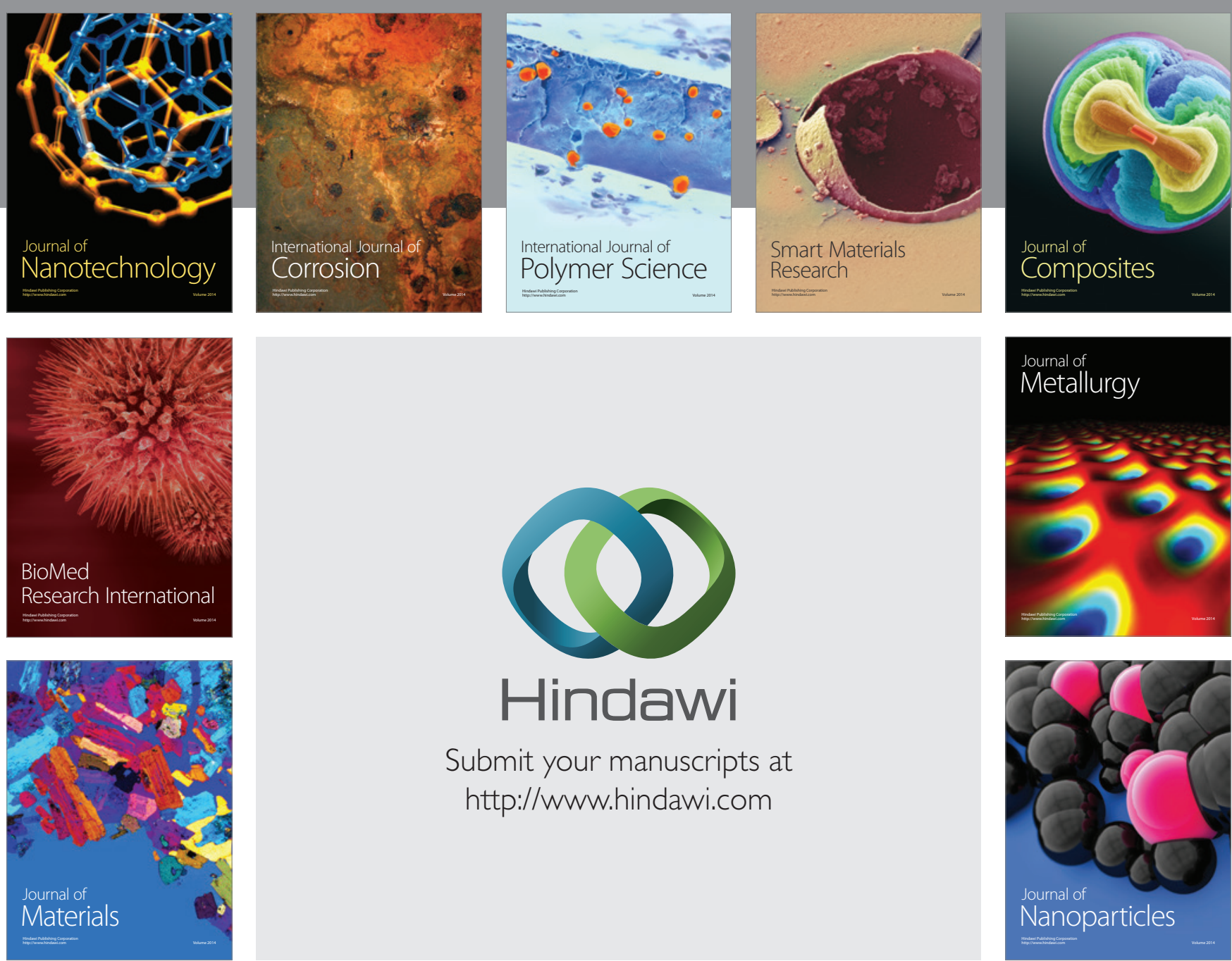

\section{Hindawi}

Submit your manuscripts at

http://www.hindawi.com

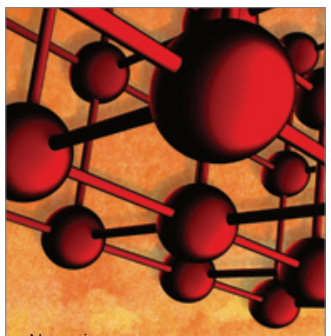

Materials Science and Engineering
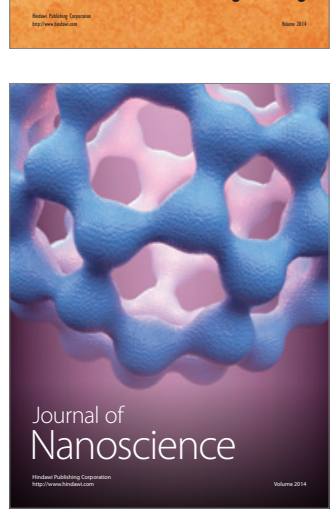
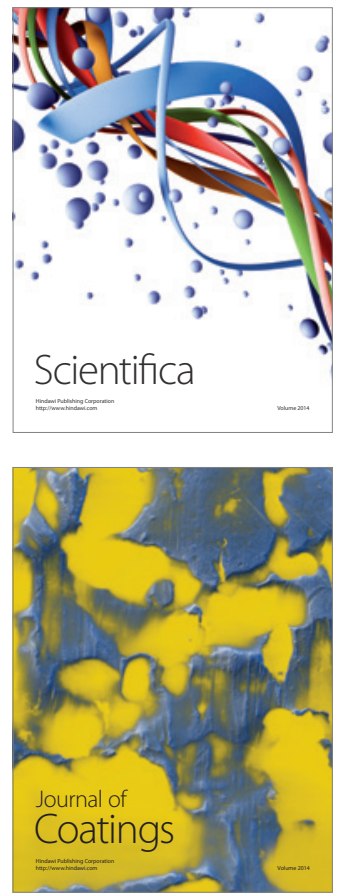
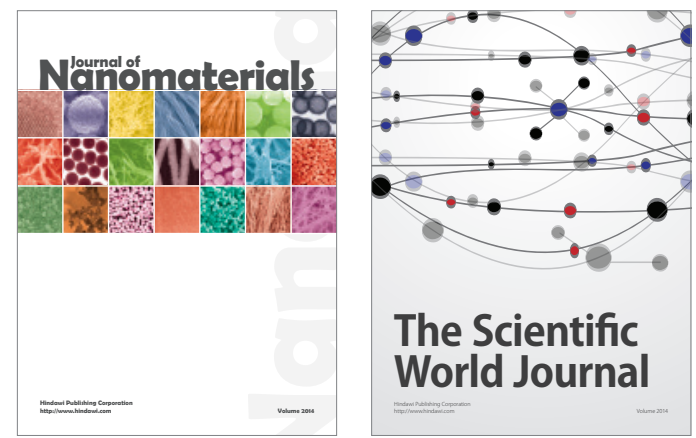

The Scientific World Journal
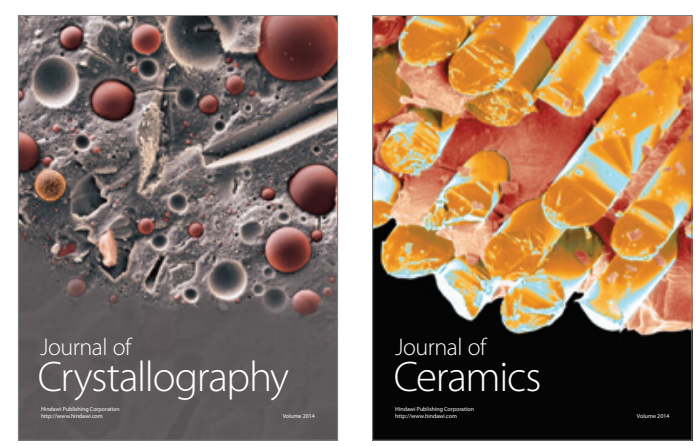
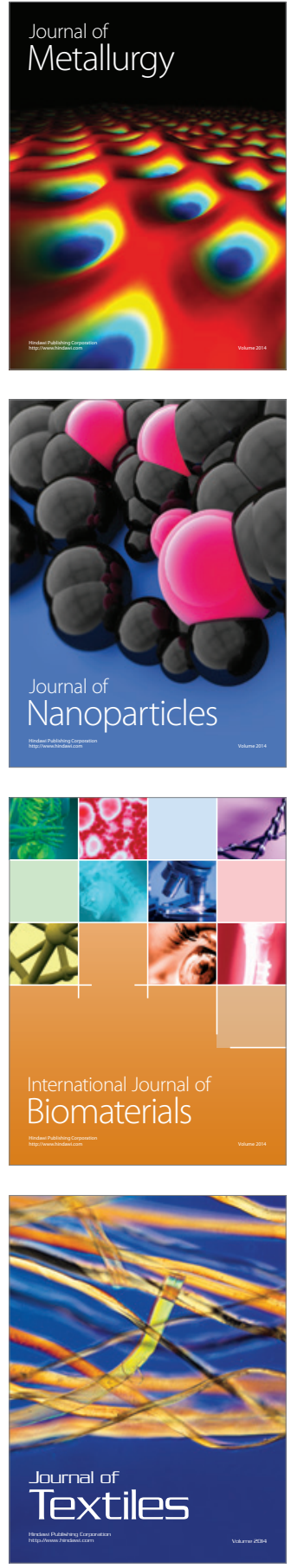